\title{
Global warming, low-frequency variability, and biennial oscillation: an attempt to understand the physical mechanisms driving major ENSO events
}

\author{
Sae-Rim Yeo $\cdot$ Kwang-Yul Kim
}

Received: 1 April 2013/Accepted: 26 June 2013/Published online: 6 July 2013

(C) The Author(s) 2013. This article is published with open access at Springerlink.com

\begin{abstract}
Three primary global modes of sea surface temperature (SST) variability during the period of 1871-2010 are identified through cyclostationary empirical orthogonal function analysis. The first mode exhibits a clear trend and represents global SST warming with an 'El Niño-like' SST pattern in the tropical Pacific. The second mode is characterized by considerable low-frequency variability in both the tropical Pacific and the North Pacific regions, indicating that there is a close connection between the two regions on interannual and decadal time scales. The third mode shows a seesaw pattern between El Niño and La Niña within a two-year period; this mode is derived by the oscillatory tendency of the tropical Pacific ocean-atmosphere coupled system. A SST reconstruction based on these three modes captures a significant portion of the SST variability in the raw data, which is primarily associated with El Niño-Southern Oscillation (ENSO) events in the tropical Pacific. Additionally, this study attempts to interpret the major ENSO events that have occurred since the 1970s in terms of the interplay originating from these three modes of variability. In particular, two key points are derived from this analysis: (1) the most extreme El Niño events occurred in 1982/1983 and 1997/1998 are attributed to the positive contributions of all three modes; and (2) the central Pacific (CP) El Niño events in the 1990s and 2000s have different physical mechanisms, that is, the CP El Niño events in the early 1990s originated mainly from the lowfrequency mode, while those in the early 2000s derived mainly from the global warming mode.
\end{abstract}

S.-R. Yeo · K.-Y. Kim $(\bowtie)$

School of Earth and Environmental Sciences, Seoul National

University, Seoul 151-747, Republic of Korea

e-mail: kwang56@snu.ac.kr
Keywords Global modes of SST - ENSO - Global warming $\cdot$ Cyclostationary EOF

\section{Introduction}

The El Niño-Southern Oscillation (ENSO) is an important phenomenon that involves variability in sea surface temperatures in the tropical Pacific Ocean, and it exerts a profound influence on the entire global climate system. Bjerknes (1969) was the first investigator who recognized that interactions between the ocean and the atmosphere in the tropical Pacific constitute ENSO, and he proposed that ENSO is a strongly coupled ocean-atmosphere phenomenon. Due to the pioneering work of Bjerknes (1969), ENSO research has made remarkable progress in recent years and the scientific community has now reached a general consensus on the fundamental features that contribute to the ENSO phenomenon (see reviews by Rasmusson and Carpenter 1982; Neelin et al. 1998). For example, ENSO exhibits oscillatory behavior in the tropical Pacific oceanatmosphere system. It is widely accepted that the occurrence frequency of ENSO peaks in approximately 3- to 5 -year periods. In addition, a secondary peak at approximately 2-year periodicity was noted by Rasmusson et al. (1990). The 2-year peak is referred to as the biennial oscillation component. The delayed oscillator hypothesis, which emphasizes the propagation of equatorially trapped waves, is thought to be an important driving mechanism for the oscillatory behavior of ENSO (Suarez and Schopf 1988; Battisti and Hirst 1989). A recharge-discharge oscillator was proposed as a transition mechanism for warm water El Niño events and cold water La Niña events in the eastern Pacific in association with dynamic mass exchange between equatorial and off-equatorial regions (Jin 1997a, b). 
While ocean-atmosphere interactions can explain the principal features of ENSO, observed characteristics of ENSO exhibit considerable irregularities. El Niño or La Niña events are often dissimilar from each other in terms of their amplitude and evolution pattern. Even over the past few decades, each ENSO event has had different characteristics. For example, the most extreme El Niño episodes in the last 100 years occurred during the recent two decades (1982/1983 and 1997/1998). However, there were no extreme La Niña episodes during this time frame, which may be indicative of an asymmetry between El Niño and La Niña. Additionally, the El Niño events that occurred in the early 1990s possessed unique characteristics in that they showed not only a prolonged persistence of warm sea surface temperature (SST) anomalies, but also a significant SST anomaly over the tropical central Pacific instead of the typical eastern Pacific region (Ji et al. 1996; Kleeman et al. 1996; Zhang et al. 1997). Previous studies suggested that diverse physical mechanisms may be contributing to these irregularities, and the proposed mechanisms include global warming (Trenberth and Hoar 1996), a decadal variability mode (Latif et al. 1997), and the influx of water from higher latitudes ( $\mathrm{Gu}$ and Philander 1997). In recent years, much attention has been aimed at understanding these new types of El Niño events that display maximum warming in the tropical central Pacific (CP) (Larkin and Harrison 2005; Kao and Yu 2009; Ashok et al. 2007; Kug et al. 2009). These so-called CP El Niño events have occurred frequently during the 1990s and 2000s (Kug et al. 2009; Yeh et al. 2009; Lee and McPhaden 2010).

The uniqueness of each ENSO event makes it difficult to comprehend the intrinsic nature of ENSO. One way to better understand the nature of ENSO is to decompose SSTs into less complicated categorical modes. Barnett (1991), for example, assumed that ENSO events correspond to three time-scale processes, that is, an annual cycle, a quasi-biennial oscillation, and a lower frequency variation pattern. Latif et al. (1997) also identified three modes for tropical Pacific SST variability through the use of a principal oscillation pattern (POP) analysis. These modes included an interannual mode, a decadal mode, and a trend or unresolved ultra-low frequency variability pattern. Kim (2002) decomposed tropical Pacific SST variability into two dominant modes - a biennial mode and a low-frequency mode-through the use of a cyclostationary empirical orthogonal function (CSEOF) analysis.

In this study, intrinsic modes of SST variability are extracted from a 140-year SST dataset covering $70^{\circ} \mathrm{S}-$ $70^{\circ} \mathrm{N}$ via CSEOF analysis for the purpose of delineating ENSO characteristics and recent changes in ENSO events. Three modes are identified: a global warming mode, a lowfrequency variability mode, and a biennial oscillation mode. Our decomposition results are similar to the three modes identified by Latif et al. (1997), but the detailed realization of each mode differs significantly from that of Latif et al. (1997). The primary goals of this study are to substantiate the physical mechanisms driving these three modes of behavior and to demonstrate how these modes jointly contribute to the unique characteristics of recently observed ENSO events.

Details regarding the CSEOF methodology are presented in the following section along with a brief description of the data used in this study. In Sect. 3, we investigate the physical mechanisms underlying the three dominant modes of SST variability identified via the CSEOF analysis. Then, observed characteristics of ENSO events since the 1970s are described in Sect. 4 in terms of the interplay of the three dominant modes of behavior. In the final section, a summary of the results is given along with a physical interpretation of the present study and its main conclusions.

\section{Data and methodology}

The primary variable analyzed in this study is SST. The $2^{\circ} \times 2^{\circ}$ resolved monthly mean SSTs for the period of 1871-2010 are obtained from the Extended Reconstruction SST, version 3 (ERSST.v3) (Smith et al. 2008). The gridded ERSST dataset was generated by a reconstruction of historical ship-based data, which were much sparser in early periods than in the modern era. In the ERSST.v3, which is the most recent version of the ERSST analysis, optimized reconstruction parameters were applied to improve the low frequency tuning to make the dataset suitable for long-term global-scale studies typical of ENSO. The SST dataset covering the near-global region $\left(0^{\circ}-360^{\circ} \mathrm{E}, 70^{\circ} \mathrm{S}-70^{\circ} \mathrm{N}\right)$ is analyzed in order to understand ENSO variability from a global viewpoint; this takes global warming and ENSO teleconnection into consideration when analyzing tropical Pacific SST variability. Atmospheric data including 1,000-hPa geopotential heights and air temperatures from 1871 to 2010 are analyzed by taking advantage of the twentieth Century Reanalysis, version 2 (Compo et al. 2011), which is provided by the NOAACIRES (National Oceanographic and Atmospheric Administration-Cooperative Institute for Research in Environmental Sciences) Climate Diagnostics Center.

To extract the principal modes of SST variability, a CSEOF analysis (Kim et al. 1996; Kim and North 1997) is applied to SST anomalies (SSTAs), which are defined as departures from the monthly climatology based on the 1871-2010 SST dataset. In this method, space-time data, $T(r, t)$, are decomposed into cyclostationary loading vectors, $L V_{n}(r, t)$, and their corresponding principal component time series, $P C_{n}(t)$, by use of the following equation 
$T(r, t)=\sum_{n} L V_{n}(r, t) P C_{n}(t)$,

The index $n$ denotes the number of a CSEOF mode, while $r$ and $t$ denote space and time, respectively. Further, the CSEOF loading vectors are periodic:

$L V_{n}(r, t)=L V_{n}(r, t+d)$,

where $d$ represents the nested period. The most distinctive aspect of the CSEOF technique, when compared to other traditional eigenvector analyses, is that each CSEOF loading vector depicts the temporal evolution related to an inherent physical process in a given dataset. While the evolution 'patterns' of a given mode are described in a CSEOF loading vector, the amplitude of the evolution is given by the corresponding PC time series. Therefore, each CSEOF mode can be viewed as the amplitude variation (PC time series) of a physical process consisting of multiple spatial patterns (loading vector).

Determining the nested period is an important step for conducting CSEOF analysis. Since there are several physical processes that exist in a dataset, the nested period should be determined such that all of the distinct periods of physical processes are covered. Specifically, this period is the least common multiple of all physical periods (not occurrence periods) in a given dataset. In this study, the nested period is set to 2 years; this decision is based on the biennial tendency of ENSO (Rasmusson et al. 1990). A detailed interpretation of the nested period is described in Kim (2002), and that study provided a reasonable physical explanation for tropical Pacific SST variability with a 2-year nested period.

Physically and dynamically consistent evolutions in atmospheric variables with the CSEOF modes of SSTAs are derived via regression analysis in CSEOF space. In this study, SST is the target variable and atmospheric variables (e.g., 1,000-hPa geopotential heights and air temperatures) are the predictor variables. After CSEOF analysis is conducted on the predictor variables, the PC time series for the first few significant modes of predictor variables, $P C P_{m}(t)$, are regressed onto the PC time series of the target variables, $P C_{n}(t)$, by use of the following equation:

$P C_{n}(t)=\sum_{m=1}^{M} \alpha_{m}^{(n)} P C P_{m}(t)+\varepsilon^{(n)}(t), \quad n=1,2,3, \ldots$

where $\alpha_{m}^{(n)}$ and $\varepsilon^{(n)}(t)$ represent the regression coefficients and the regression error time series, respectively. The regression coefficients are determined such that the variance of the regression error time series is minimized. Then, the regressed loading vectors for the predictor variable, $L V P R_{n}(r, t)$, are obtained using the regression coefficient as described in Eq. (4):
$\operatorname{LVPR}_{n}(r, t)=\sum_{m=1}^{M} \alpha_{m}^{(n)} L V P_{m}(r, t)$

where $L V P_{m}(r, t)$ represent the CSEOF loading vectors for the predictor variable. As a result of regression analysis in CSEOF space, a predictor variable can be rewritten as:

$P(r, t)=\sum_{n} L V P R_{n}(r, t) P C_{n}(t)$,

Thus, entire variables can be written as:

$\operatorname{Data}(r, t)=\sum_{n}\left\{T_{n}(r, t), Z_{n}(r, t), U_{n}(r, t), V_{n}(r, t), \ldots\right\} P C_{n}(t)$,

where the terms enclosed in the brackets denote the evolution of the $n$th mode as was manifested by the different variables. Evolutions in the different variables are considered to be physically consistent with each other.

\section{Three fundamental modes of SST variability}

\subsection{Global warming mode}

Dominant modes of SST variability over the near-global domain $\left(0^{\circ}-360^{\circ} \mathrm{E}, 70^{\circ} \mathrm{S}-70^{\circ} \mathrm{N}\right)$ during a 140 -year period (1871-2010) are calculated using CSEOF analysis. Figure 1 represents the first CSEOF mode of SSTAs, which explains approximately $24 \%$ of the total variance in the dataset. Since the nested period is set to 2 years, each CSEOF loading vector depicts SSTA patterns for 24 months. For the sake of brevity, 3-month averaged SSTA patterns are presented in Fig. 1a. As shown in Fig. 1a, positive SSTAs are found everywhere except for in a relatively small region of the central North Pacific and the North Atlantic where subtle negative SSTAs are observed. Warming is conspicuous in the northern Indian Ocean, the tropical Pacific Ocean, and the southern Atlantic Ocean. These global warming patterns do not exhibit significant monthly evolution. The corresponding PC time series (Fig. 1b) shows a clear increasing trend since 1910, indicating that this mode contains a global SST warming signature.

Strikingly, the warming pattern in the tropical Pacific features an El Niño-like signal with stronger warming in the eastern tropical Pacific than in the western tropical Pacific. Recently, the issue of tropical Pacific SST responses to global warming has received much attention. While it is still controversial whether or not the SST responses are El Niño like (i.e., stronger warming in the tropical eastern Pacific) or La Niña like (i.e., stronger warming in the tropical western Pacific), the majority of 
Fig. 1 a The loading vector $\left(0^{\circ}-360^{\circ} \mathrm{E}, 70^{\circ} \mathrm{S}-70^{\circ} \mathrm{N}\right)$, b the corresponding PC (principal component) time series, and c the longitude-time cross section averaged over the equatorial region $\left(5^{\circ} \mathrm{S}-5^{\circ} \mathrm{N}\right)$ for the first CSEOF

(cyclostationary empirical orthogonal function) mode of SST (sea surface temperature) anomalies. This mode represents global warming/ cooling

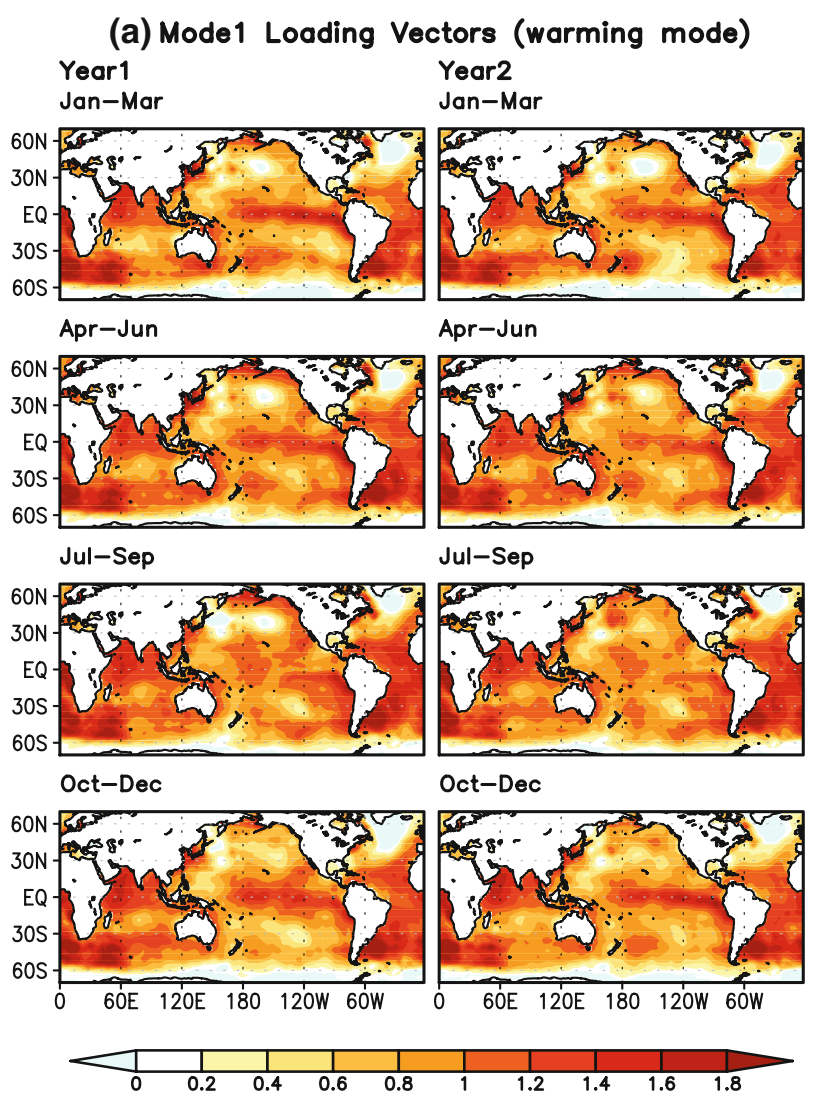

(b) Mode1 PC time series

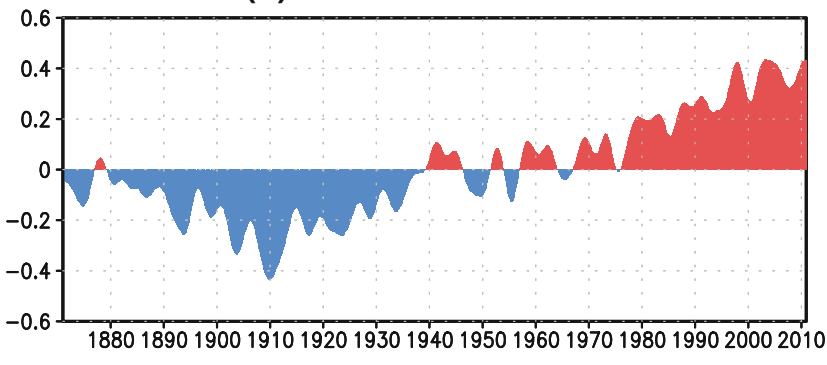

(c) Recon. SST(5S-5N)

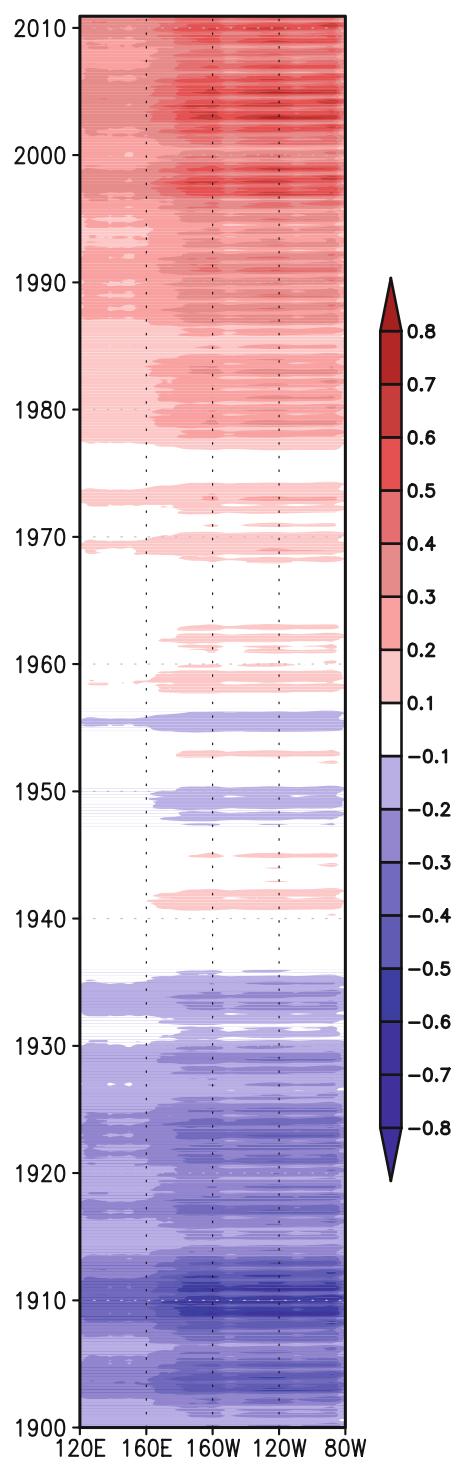

the climate models project El Niño-like warming in response to increasing greenhouse gas concentrations in the atmosphere (Meehl and Washington 1996; Timmermann et al. 1999; Cai and Whetton 2000; Boer et al. 2004; Collins 2005). The most plausible and widely accepted mechanism for El Niño-like warming was suggested in Meehl and Washington (1996). This study proposed that negative cloud-albedo feedback in the western Pacific warm pool region could be responsible for stronger warming in the tropical eastern Pacific, which would create an El Niño-like pattern. Both the El Niño-like warming pattern and the increasing PC time series associated with the first CSEOF mode signify a warming signal in the historical dataset.

It should be noted, however, that the PC time series of the first CSEOF mode does not depict a linear trend; there appears to be multi-decadal as well as interannual variability superimposed on the warming trend (Fig. 1b). These data imply that the first CSEOF mode does not merely reflect a linear trend in the historical SST dataset. Likewise, Deser et al. (2010) examined linear SST trends in several historical SST datasets over the period of 1900-2008, and the extracted SST trends in the twentieth century did not exhibit robust El Niño-like warming patterns (see Fig. 1 in Deser et al. 2010). Even though a large portion of the first CSEOF mode is associated with increasing SSTs, the first CSEOF mode should not be construed as a linear trend for SSTs.

The SST variability associated with the first CSEOF mode can be easily understood by the corresponding reconstruction of SSTAs. The SSTA field is reconstructed by multiplying the loading vector with the corresponding PC time series (note that the loading vector is periodic). 
Figure 1c shows the longitude-time plot of the reconstructed SSTAs averaged over $5^{\circ} \mathrm{S}-5^{\circ} \mathrm{N}$. These results show pronounced warming in the tropical Pacific, which reaches the highest level during the 2000s.

\subsection{Low-frequency variability mode}

Figure 2 shows the second CSEOF mode, which explains approximately $13 \%$ of the total variance in the SST dataset. The spatial pattern of the second CSEOF mode shown in Fig. 2a does not change significantly within the nested period. Thus, this mode may be considered to be approximately stationary. The SSTA pattern is quite similar to well-known ENSO features that show strong positive SSTAs over the tropical eastern and central Pacific. There are, however, some notable differences between the second CSEOF mode and conventional ENSO features. The SSTA pattern in the tropical region is broader in the meridional direction than in the conventional ENSO signal, and the positive anomalies extend from the northeastern to the southeastern mid-latitude Pacific. Also, Fig. 2a depicts stronger SSTAs in the tropical central Pacific (see also Fig. 2c), which correspond to typical features observed during CP El Niño events.

Significant SSTAs appear not only in the tropical Pacific, but also in the North Pacific and the South Pacific. Note that the second mode does not account for much of the variance in the Indian and Atlantic Oceans. The SSTA in the South Pacific shows a dipole-like structure in the meridional direction with positive SSTA to the south of $45^{\circ} \mathrm{S}$ and negative SSTA to the north of $45^{\circ} \mathrm{S}$. The SSTA pattern in the North Pacific has a negative anomaly with an elliptical shape over the western to central North Pacific and a positive anomaly along the eastern North Pacific. This pattern is similar to the structure of the Pacific Decadal Oscillation (PDO) (Mantua et al. 1997), which represents the primary decadal mode of the North Pacific. This similarity can be confirmed through comparisons of the PDO index (available online at http://jiaso.washington.edu/ pdo/PDO.latest) with the PC time series of the second CSEOF mode (shading in Fig. 2b). The PC series is strongly correlated at a 0.64 level with the 2 -year moving average data from the monthly PDO index (data not shown). To further investigate characteristics of the second CSEOF mode, correlations between the PC time series and the monthly Nino3 index (SSTA averaged over $90^{\circ}-$ $150^{\circ} \mathrm{W}, 5^{\circ} \mathrm{S}-5^{\circ} \mathrm{N}$ ) are calculated. Correlation of the two time series is 0.45 (data not shown), and it increases markedly to 0.84 when a 5-year low-pass filter is applied to the Nino3 index after the linear trend is removed (dashed line in Fig. 2b).

High correlations of the PC time series with the PDO index and the low-pass filtered Nino3 index suggest that the second CSEOF mode represents a connection between low-frequency variability of the tropical and the North Pacific. There is a growing body of evidence that suggests that the low-frequency variability of ENSO is largely modulated by decadal variability in the North Pacific $(\mathrm{Gu}$ and Philander 1997; Latif et al. 1997; Barnett et al. 1999; Kleeman et al. 1999; Pierce et al. 2000; Vimont et al. 2003). In this respect, the second CSEOF mode may signify a link between the tropical Pacific and the North Pacific on interannual and decadal time scales.

Figure 2c displays the longitude-time cross section of tropical Pacific $\left(5^{\circ} \mathrm{S}-5^{\circ} \mathrm{N}\right)$ SSTAs reconstructed from the second CSEOF mode. The data in this figure show primarily interdecadal fluctuations of tropical Pacific SSTAs, although weak intradecadal variability is also observed. In recent decades, transitions occurred in 1976/1977 from a cold to a warm phase, and from a warm to a cold phase in 1998/1999. These phase transitions are also evident in the PDO variability. The 1976/1977 transition is particularly noteworthy in the PDO index, which has been termed a climatic 'regime shift' (Miller et al. 1994). Also, substantial evidence supports the idea that physical conditions in the North Pacific changed around 1998/1999 (Minobe 2000; Schwing and Moore 2000; Bond et al. 2003; Peterson and Schwing 2003). The evidence from these studies further confirms that the second CSEOF mode constitutes a connection between the tropical Pacific and the North Pacific on interannual and decadal time scales.

\subsection{Biennial oscillation mode}

Figure 3 shows the third CSEOF mode, which explains approximately $8 \%$ of the total variance in the SST dataset. In contrast to the first and the second CSEOF modes, the spatial patterns of the third mode exhibit a clear oscillation within the nested period (Fig. 3a). The SSTA evolution patterns portray the development of El Niño and La Niña events and show details of the phase transitions between the two. During the spring (April-June) of year 1, a warm SSTA develops in the eastern tropical Pacific off the coast of Peru. This warm anomaly grows towards the central tropical Pacific during successive months (July-September), and reaches its maximum amplitude by the end of the calendar year (October-December). After El Niño reaches a mature stage, negative feedback mechanisms work to reset the thermocline depth in the tropical Pacific and terminate the El Niño phase. The negative feedback mechanisms are described in the context of a delayed oscillator (Suarez and Schopf 1988; Battisti and Hirst 1989) and a recharge-discharge oscillator (Jin 1997a, b). Subsequently, negative feedback results in cold SST anomalies in the eastern tropical Pacific as is observed during the spring (April-June) of year 2. This negative SSTA develops 
Fig. 2 The data presented are similar to the data in Fig. 1 but are for the second CSEOF mode. The dashed line in b represents the 5-year low-pass filtered Nino3 index after removing a linear trend. This mode represents low-frequency SST variability in the Pacific (a) Mode2 Loading Vectors (low-frequency mode)
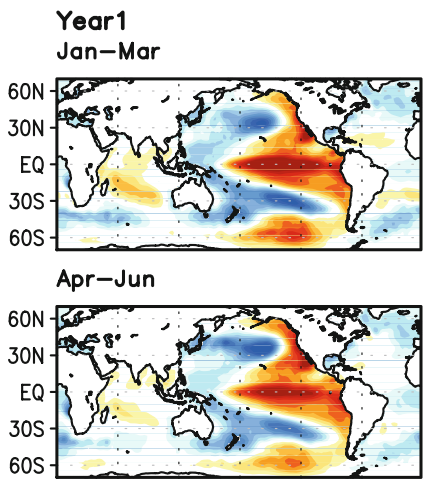
Year2

Jan-Mar

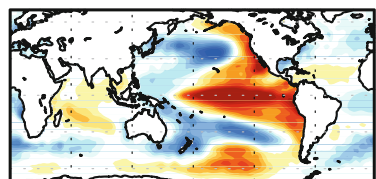

Apr-Jun

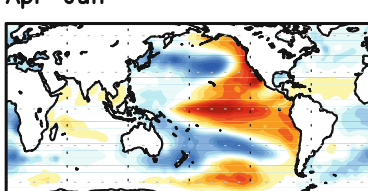

$$
\text { Jul-Sep }
$$

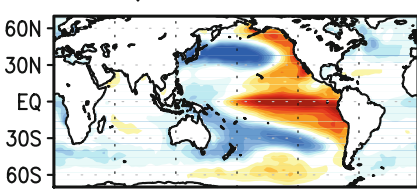

605

$$
\text { Oct-Dec }
$$

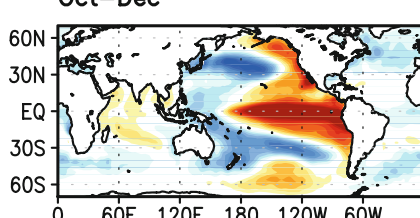

Jul-Sep

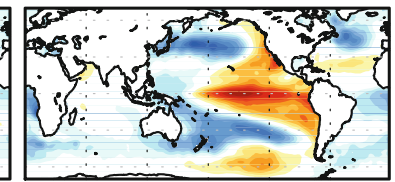

Oct-Dec
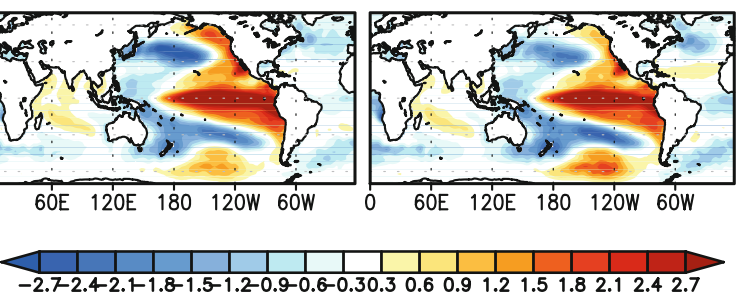

(b) Mode2 PC time series

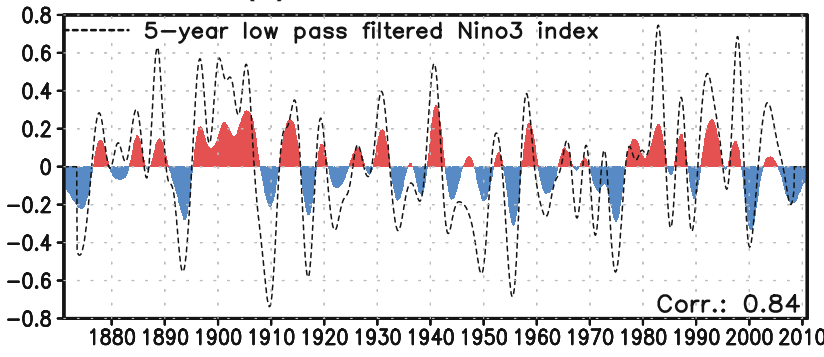

(c) Recon. SST(5S-5N)

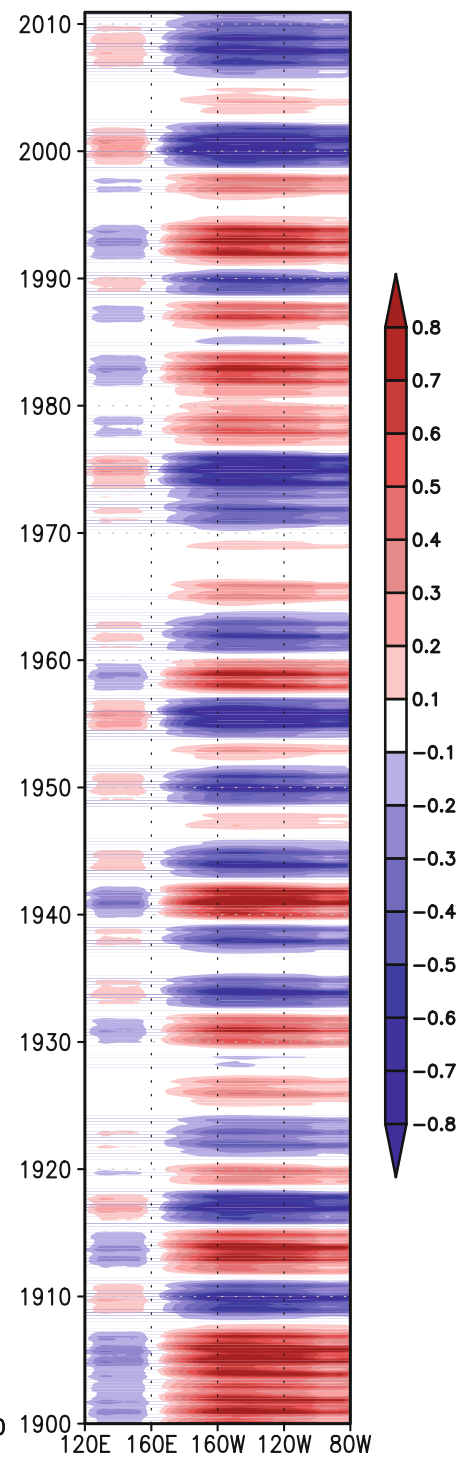

toward the central tropical Pacific until it matures in the winter (October-December) of year 2.

In addition to the oscillatory nature of the third CSEOF mode, several aspects of the third mode demonstrate that this mode fits the description of a canonical ENSO. First, the intensity of the SST change is confined to a narrow equatorial zone, while the SSTA in the northern North Pacific is relatively weak (Fig. 3a). Second, the SSTA over the Indian Ocean lags behind the ENSO signal by about one season. The warm SSTA in the Indian Ocean first appears during the mature stage of El Niño development (October-December in year 1) and peaks during the decaying phase (January-March in year 2). The warm SSTA in the Indian Ocean persists during the transition stage from El Niño to La Niña (April-June in year 2). Previous studies suggested a feedback process between the
Indian Ocean SSTA and ENSO that a warming in the Indian Ocean, which is a part of an El Niño signal, plays a role in the transition of an El Niño into a La Niña via easterly wind stress over the western Pacific (Kug and Kang 2006; Yoo et al. 2010; Kim et al. 2011).

The characteristics of the third CSEOF mode described above are classical features associated with conventional ENSO events (e.g., Rasmusson and Carpenter 1982). In fact, this mode is nearly identical to the one identified in Kim (2002). The Kim (2002) study focused on the similarity of the CSEOF mode and the biennial component of the tropical Pacific variability addressed by Rasmusson et al. (1990). The third CSEOF mode identified in this study, therefore, is termed the biennial oscillation mode following the nomenclature used by Rasmusson et al. (1990). 
Fig. 3 The data presented are similar to the data in Fig. 1 but are for the third CSEOF mode. This mode represents primarily the biennial oscillations (tendency) of SST in the tropical Pacific

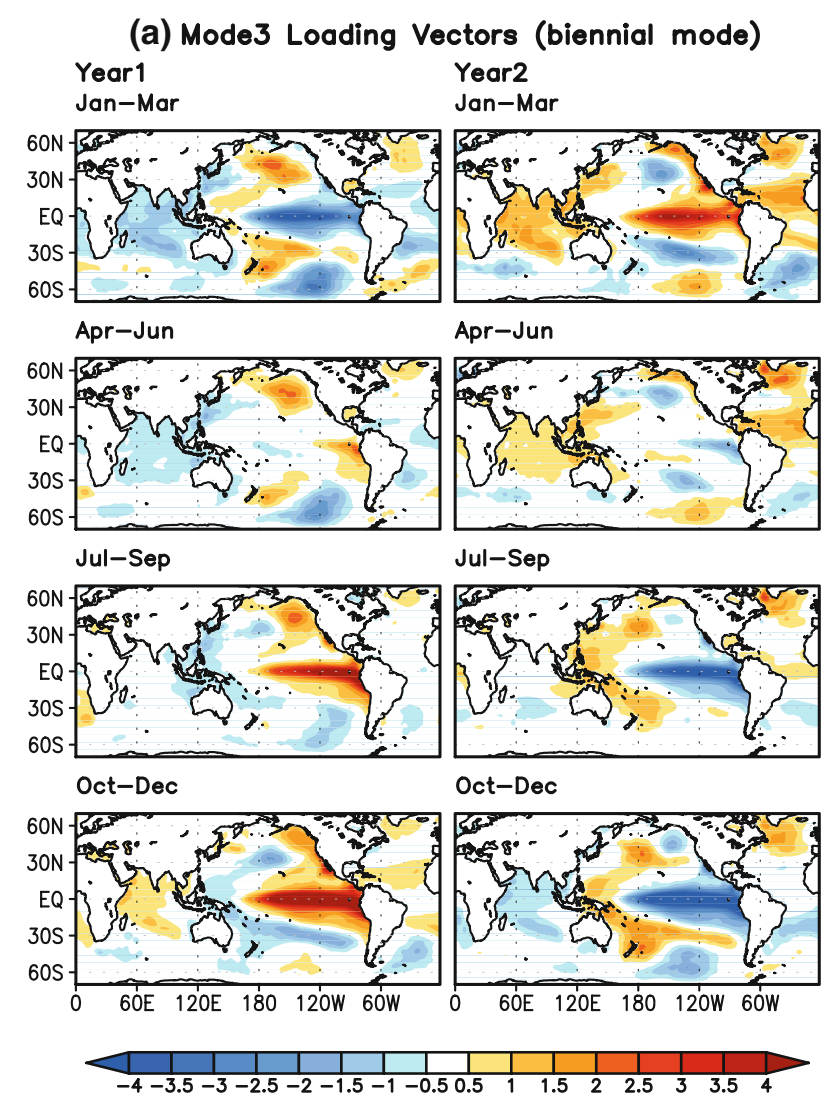

(b) Mode3 PC time series

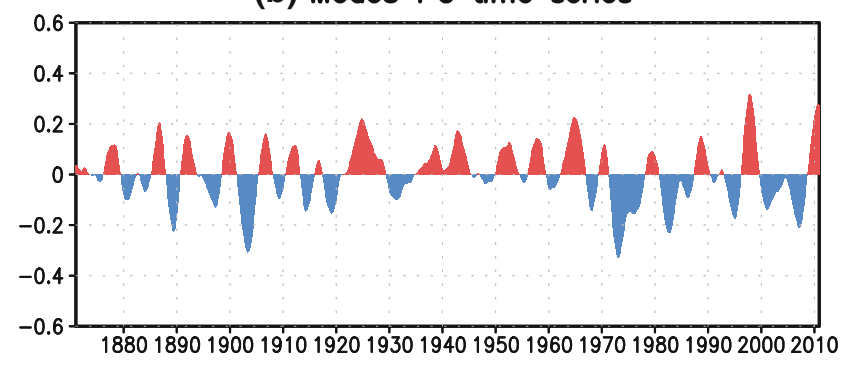

(c) Recon. SST(5S-5N)

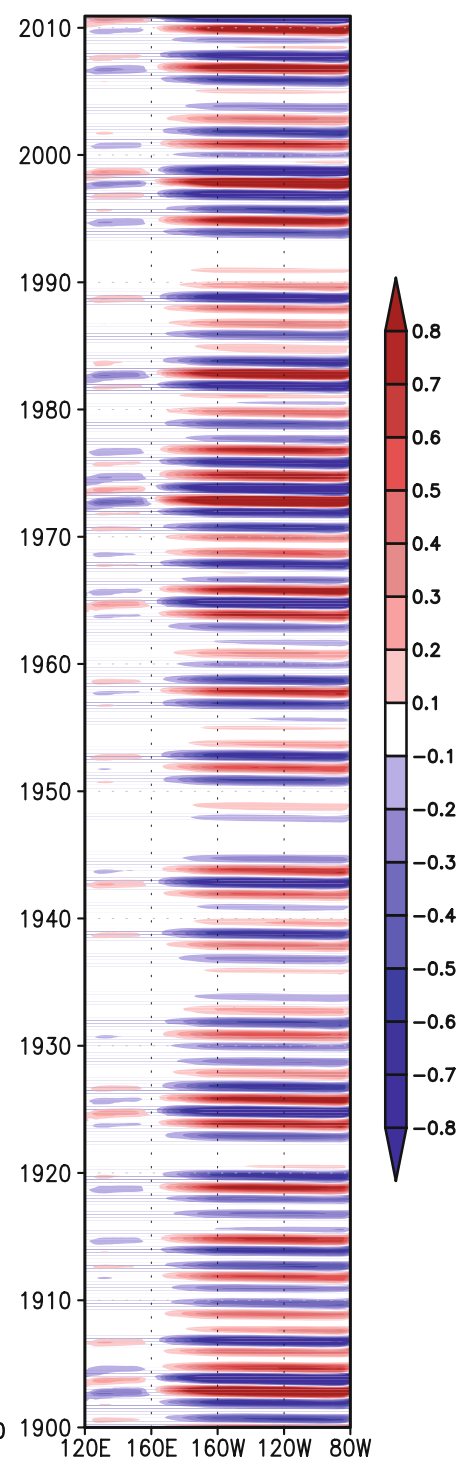

Figure 3c shows the reconstructed SSTAs averaged over the tropical Pacific region. These data confirm that the third CSEOF mode constitutes biennial oscillations of SSTAs in the tropical Pacific, although not all biennial oscillations are necessarily in phase. The PC time series of the third CSEOF mode is presented in Fig. 3b, which shows that the amplitude of the biennial oscillation underwent long-term variations.

\subsection{Independence of the three modes and their relevance to tropical Pacific SSTA}

The three dominant modes of the near-global SST variability identified via CSEOF analysis are the global warming mode, the low-frequency variability mode, and the biennial oscillation mode. The SSTA evolution patterns in the loading vectors of the three modes are different from each other as was discussed above. In particular, a biennial SSTA phase transition is characteristic of the third CSEOF mode and warm water anomalies are frequent almost every other year. In contrast, the SSTAs associated with the second CSEOF mode exhibit the same sign over two-year periods. Interestingly, the spatial patterns of these two modes are strongly correlated with each other. The differences between the modes could not be realized when the nested period was set to 1 year. Hence, the nested period is set to 2 years in the present study.

Although the three modes are temporally uncorrelated with each other, they do not necessarily represent independent modes of SST variability. Their independence can be tested by calculating the lead-lag correlation among the PC time series as is plotted in Fig. 4. The correlation coefficients between the PC time series of the first and third modes (blue 


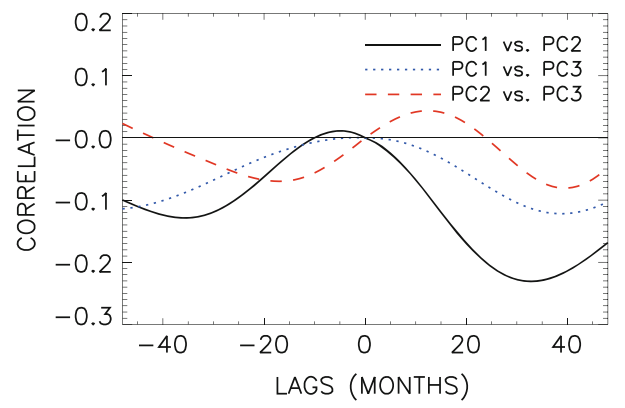

Fig. 4 Lead-lag correlation among the first three CSEOF PC time series

dotted line) and the second and third modes (red dashed line) are insignificant at a $99 \%$ confidence level $(r \approx 0.11)$ for almost all lags. Although correlations of the first and second PC time series are not entirely negligible for all lags (black solid line), the correlations are generally insignificant. These results confirm that the three modes are nearly independent of each other. Therefore, the three principal modes of SSTAs extracted via CSEOF analysis seem to have originated from independent sources or were driven by different physical mechanisms of variability.

To examine how much of the total variability of tropical Pacific SSTAs can be explained by the three CSEOF modes, SSTAs are reconstructed by summing the data from three modes and comparing the results to the raw data. Figure $5 \mathrm{a}$ and $\mathrm{b}$ display the longitude-time cross sections of the SSTAs that are averaged over the equatorial region $\left(5^{\circ} \mathrm{S}-5^{\circ} \mathrm{N}\right)$ for the raw data and the reconstructed data, respectively. The three modes together reasonably reproduce the observed SSTAs, which primarily are associated with ENSO variability. To further confirm this similarity, the Nino3 and Nino4 $\left(160^{\circ} \mathrm{E}-150^{\circ} \mathrm{W}, 5^{\circ} \mathrm{S}-5^{\circ} \mathrm{N}\right)$ indices from the reconstructed SSTA data (orange curves in Fig. $5 \mathrm{c}$ and d) are compared with the original indices from the raw SST anomaly data (black curves in Fig. 5c and d). The correlations between the reconstructed and the raw data are 0.86 and 0.83 for the Nino3 and Nino4 indices, respectively. These results indicate that the three-mode reconstruction captures a significant portion of the observed ENSO variability. As can be seen in Fig. 5, the majority of SST variability over the tropical Pacific can be decomposed into three modes (i.e., the global warming mode, the low-frequency variability mode, and the biennial oscillation mode) that likely originated from statistically independent physical mechanisms.

\subsection{Distinct physical responses to the three SSTA modes}

To examine the atmospheric variability associated with the SSTA for the three CSEOF modes, regression analysis in
CSEOF space was conducted. Due to the distinct physical natures of the three modes, atmospheric variability differs significantly in magnitude and pattern among the three modes. Figure 6 displays the winter (December, January, and February) patterns of SSTAs for the three modes and the corresponding regression patterns of precipitation anomalies. The spatial patterns are scaled such that the variance of the corresponding PC time series is unity. Thus, the patterns reflect the relative magnitude of anomalies associated with the three modes. While all three modes depict central and eastern tropical Pacific warming (Fig. 6a-c), the associated precipitation anomaly patterns differ appreciably. For example, the precipitation anomalies associated with the global warming mode differ significantly in pattern and magnitude from those of the other two modes. As shown in Fig. 6e, the positive anomaly over the equator is quite weak, and is confined to the tropical central Pacific, while the stronger positive precipitation anomaly is elongated to the eastern Pacific in the second and third modes (Fig. 6f, g). The precipitation anomalies corresponding to the low-frequency variability mode and the biennial oscillation mode exhibit similar featurespositive anomalies over the central and eastern Pacific and negative anomalies over the western Pacific (Fig. 6f, g). However, the difference of the precipitation anomalies (Fig. 6h) shows that the detailed feature and magnitude of precipitation differs from each other despite the similarity of the SSTA pattern (Fig. 6d). In particular, the magnitude of the negative precipitation anomaly over the maritime continent and the positive anomaly over the tropical central Pacific is stronger in the biennial oscillation mode than in the low-frequency variability mode.

The regression patterns of air temperature, geopotential height, and wind also differ substantially among the three modes (Fig. 7). A similarity in SSTA patterns over the tropical Pacific is obvious between the low-frequency variability and the biennial oscillation modes (Fig. 6b, c). Nonetheless, the atmospheric circulation and air temperature patterns associated with these two modes differ appreciably from each other. Previous studies on ENSOrelated atmospheric teleconnection revealed that the Aleutian Low becomes stronger during an El Niño event (Lau and Nath 1996; Alexander et al. 2002). As shown in Fig. $7 \mathrm{~b}$ and $\mathrm{c}$, the Aleutian Low observed at the 1,000-hPa level is intensified as expected, but the position and magnitude of the intensification differ between the two modes. The anomalous Aleutian Low in the biennial oscillation mode is centered further northward and covers a smaller area of the North Pacific compared to that in the lowfrequency variability mode.

Due to different atmospheric circulation patterns, the regressed air temperature anomalies for modes two and three also differ in pattern and magnitude (shadings in 
Fig. 5 Longitude-time cross section of SSTA (SST anomalies) averaged over the equatorial region $\left(5^{\circ} \mathrm{S}-5^{\circ} \mathrm{N}\right)$ of a the raw data, and $\mathbf{b}$ the reconstructed data based on the first three modes. c Nino3 and d Nino4 indices obtained from the raw SSTA data (black line) and the 3-mode SSTA reconstruction (orange line)

$\operatorname{SST}(5 S-5 N)$

(a) Raw SST

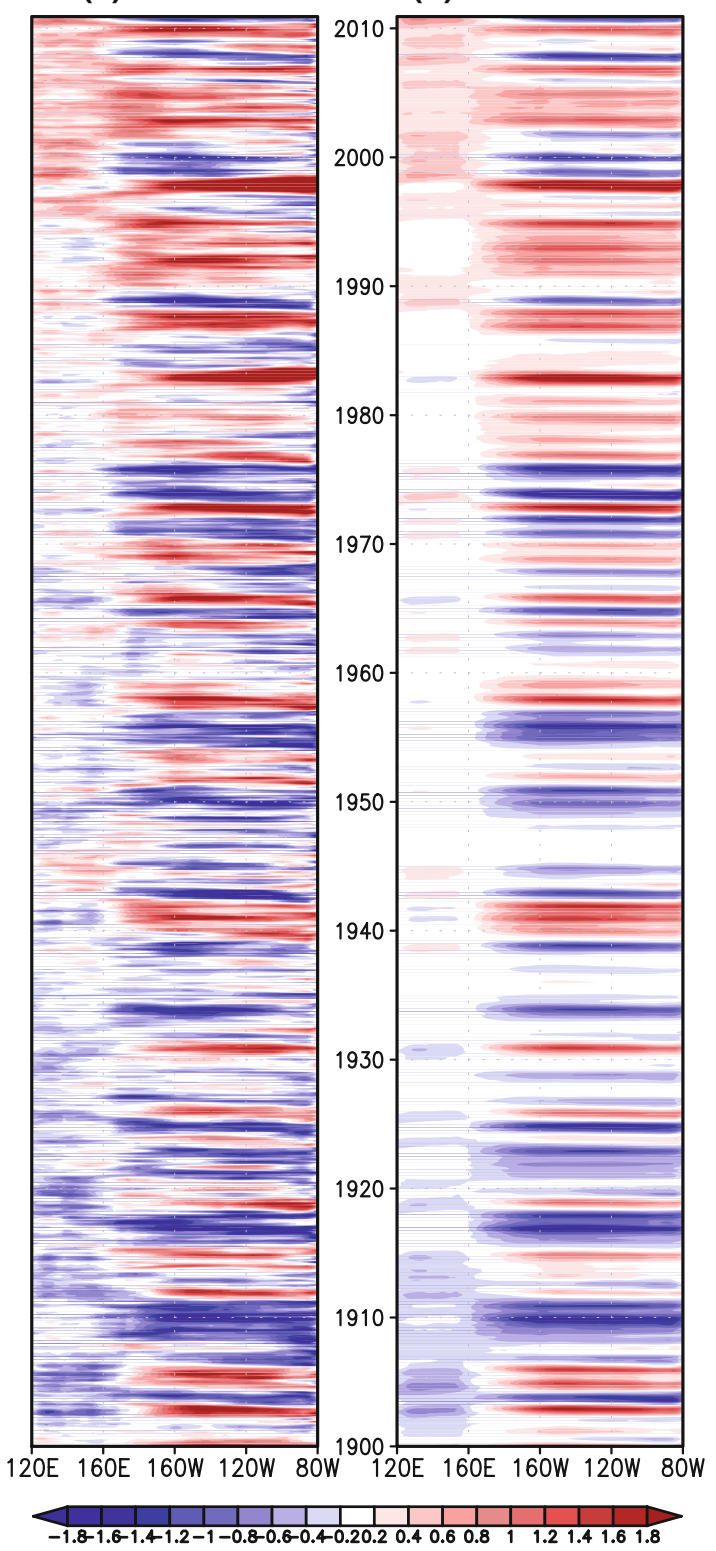

Index

(c) Nino3

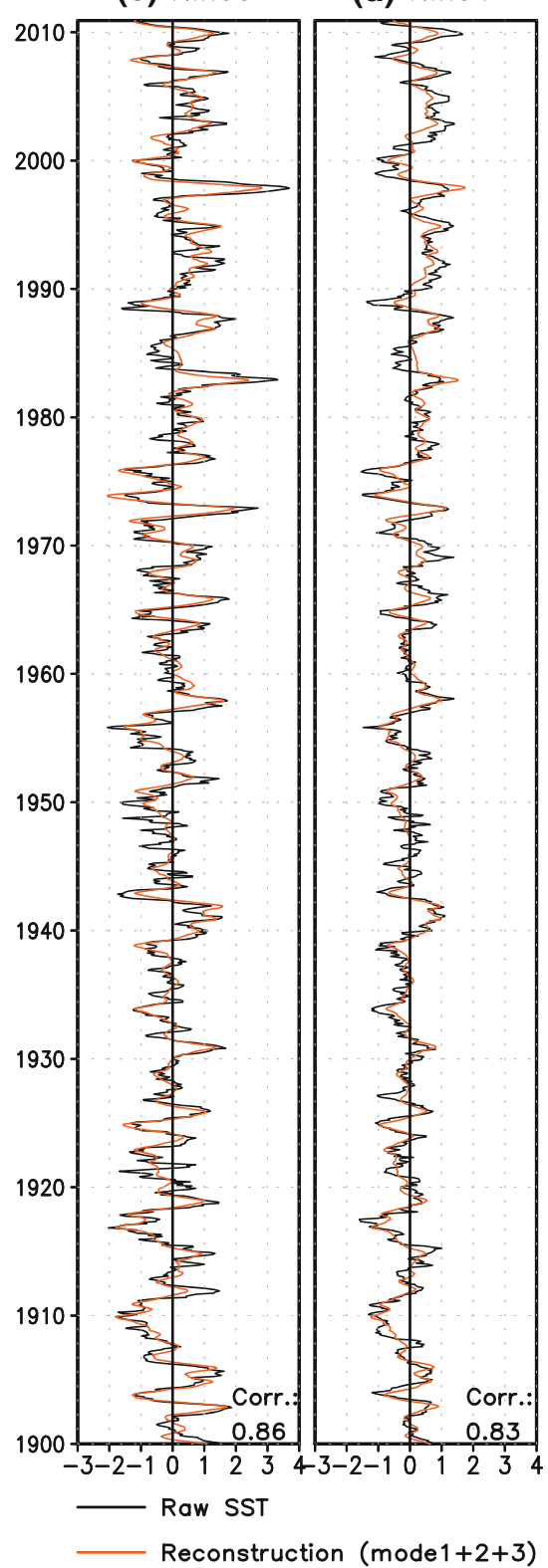

Fig. 7b, c). In the low-frequency variability mode, a positive temperature anomaly prevails over the western United States while a negative temperature anomaly is seen over the southeastern United States. In the biennial oscillation mode, on the other hand, an intense positive temperature anomaly is present over Canada. Significant differences are also observed over the Asian continent. Differences in the atmospheric variability associated with the two modes are shown in Fig. $7 \mathrm{~d}$ and $\mathrm{h}$. The atmospheric teleconnection patterns for the low-frequency and biennial modes differ critically despite the similarity of the SSTA patterns over the tropical Pacific. Therefore, the distinction of these three modes will be crucial not only for ENSO forecasting, but also for understanding teleconnection patterns and terrestrial responses to ENSO.

\section{Characterization of recent ENSO events}

A primary objective of the present study is to understand how the three principal modes of SSTAs contribute to the major ENSO events that have occurred in recent years. The contribution of each of the three modes to the observed ENSO variability is presented in Fig. 8. Figure $8 \mathrm{a}-\mathrm{c}$ display longitude-time cross sections of the three modes of tropical Pacific $\left(5^{\circ} \mathrm{S}-5^{\circ} \mathrm{N}\right)$ SSTAs, respectively, and 
Fig. 6 The a first, b second, and $\mathbf{c}$ third CSEOF loading vectors of SSTA and the map of regressed precipitation anomalies corresponding to the e first, $\mathbf{f}$ second, and $\mathbf{g}$ third CSEOF modes of the SSTA. The SSTA and precipitation differences between the third and second CSEOF modes (mode 3-mode 2) are presented in $\mathbf{d}$ and $\mathbf{h}$, respectively. The presented patterns represent averages from December to February. The CSEOF and regression patterns are scaled by the standard deviation of the respective $\mathrm{PC}$ time series (eigenvalues) so that the PC time series have a unit variance
SEA SURFACE TEMPERATURE

(a) MODE 1

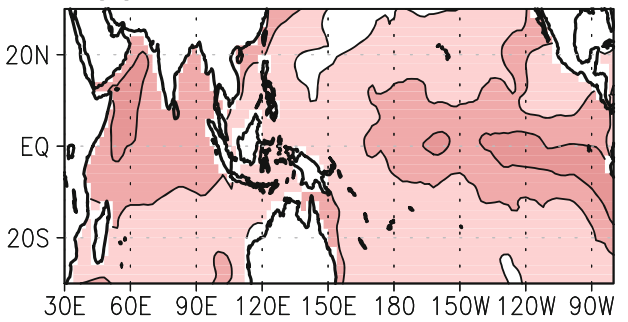

(b) MODE 2

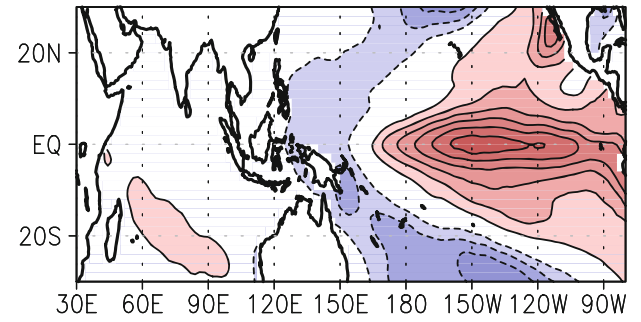

(c) MODE 3

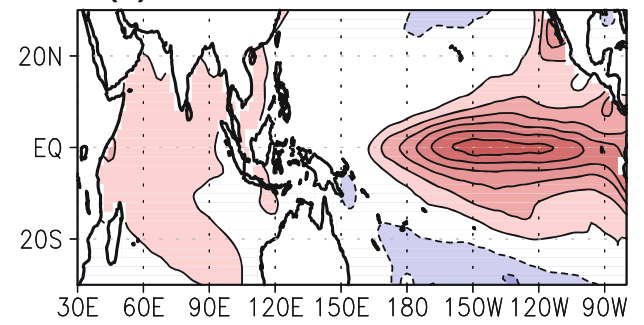

(d) MODE 3 - MODE 2

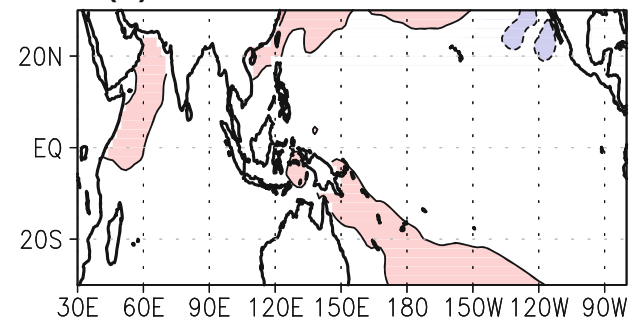

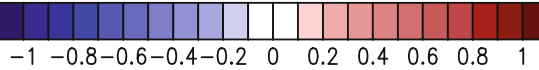

PRECIPITATION

(e) MODE 1

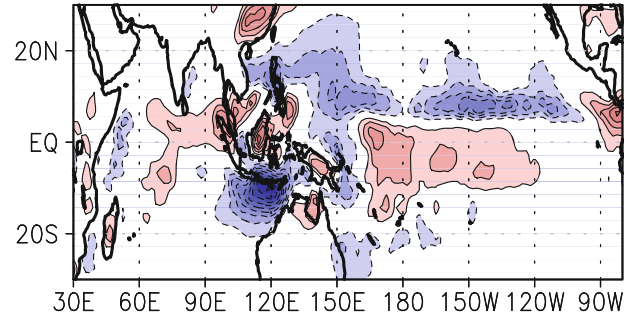

(f) MODE 2

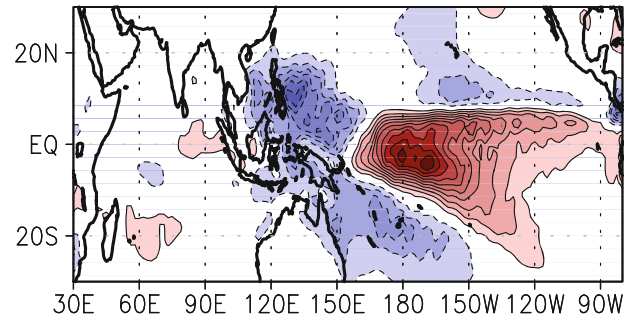

(g) MODE 3

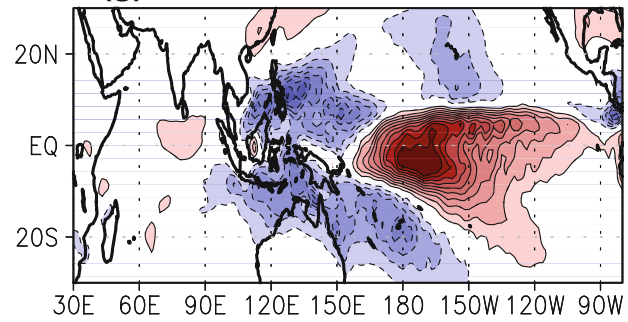

(h) MODE 3 - MODE 2

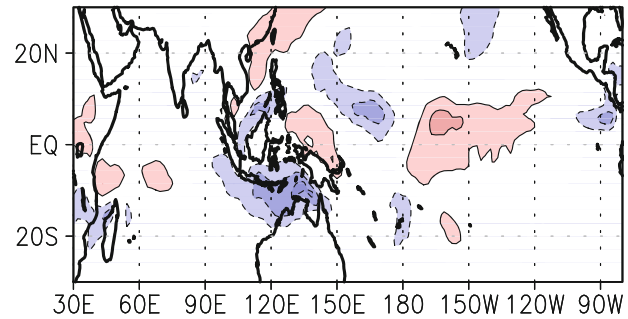

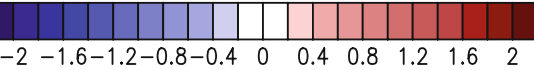

Fig. 8d shows the winter-mean (averages from December to February) Nino3 and Nino4 indices calculated from the raw SSTA data. The data presented in Fig. 8 is for the period of 1955-2010, since the main focus of this analysis is on the major ENSO events during the most recent decades. Figure 8 provides insight into how the interplay of the three principal modes (i.e., the global warming mode, the low-frequency variability mode, and the biennial oscillation mode) determines the observed characteristics of ENSO events.

The low-frequency variability mode shows multiple phase transitions during the data period analyzed (Fig. 8b). Since 1977, a warming trend is clear and it is associated with the global warming mode (Fig. 8a). Meanwhile, the magnitude of the biennial oscillation mode varies in time without any obvious trends or phase transitions (Fig. 8c). The biennial oscillation mode exhibits marked warming during strong El Niño years (1982/1983 and 1997/1998). Note that there is also remarkable warming in the biennial oscillation mode during 1972/1973, and that this warm anomaly is larger than those observed in 1982/1983 and $1997 / 1998$. Nonetheless, the $1972 / 1973$ El Niño was not as strong as the $1982 / 1983$ or $1997 / 1998$ events according to the Nino3 index (Fig. 8d). One major difference among the $1972 / 1973$, the $1982 / 1983$, and the $1997 / 1998$ events is found in the low-frequency variability mode. For the 1972/1973 El Niño, a strong negative SST anomaly from the low-frequency variability mode offsets a strong 
Fig. 7 The map of regressed air temperature (shade) and geopotential height anomalies (contour) at 1,000-hPa (left column), and the map of stream function (contour) and geopotential height anomalies (shade) at $200-\mathrm{hPa}$ (right column) for the first (a and e), second (b and f), and third (c and $\mathbf{g}$ ) CSEOF modes of SSTA, respectively. The difference between the third and second CSEOF modes (mode 3 mode 2) are presented in $\mathbf{d}$ for $1,000 \mathrm{hPa}$ air temperature and geopotential height, and $\mathbf{h}$ for $200 \mathrm{hPa}$ geopotential height and wind. The presented patterns represent averages from December (year 1) to February (year 2). The CSEOF and regression patterns are scaled by the standard deviation of the respective $\mathrm{PC}$ time series (eigenvalues) so that the PC time series have a unit variance
1000 hPa T \& GEOP. HEIGHT

(a) MODE 1

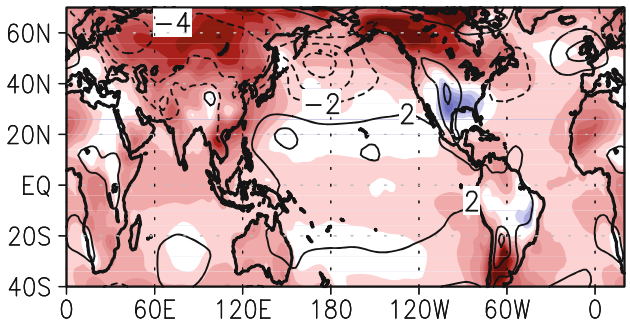

(b) MODE 2

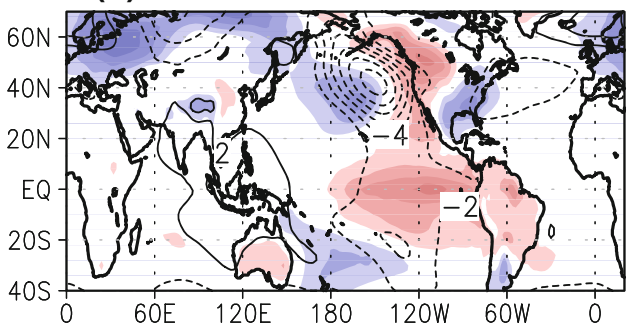

(c) MODE 3

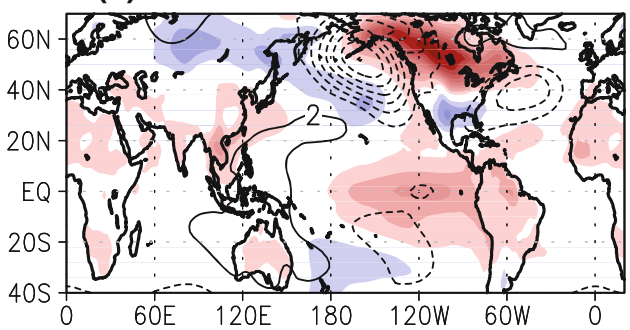

(d) MODE 3 - MODE 2

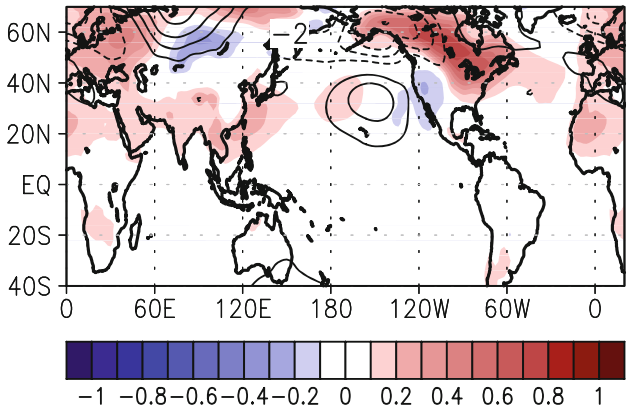

$200 \mathrm{hPa}$ GEOP. HEIGHT \& (U,V)

(e) MODE 1

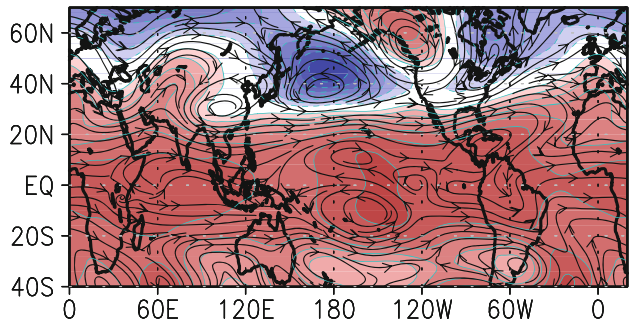

(f) MODE 2

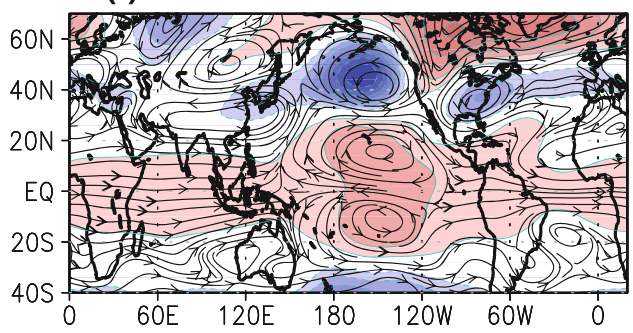

(g) MODE 3

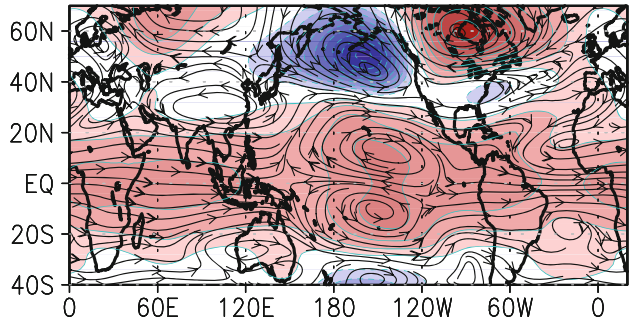

(h) MODE 3 - MODE 2

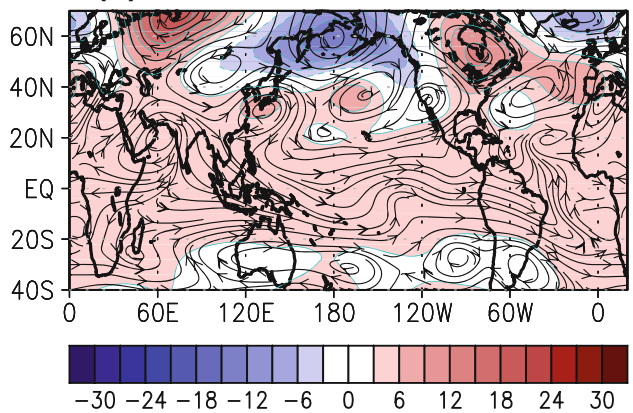

positive anomaly from the biennial oscillation mode. As a result, warming during the 1972/1973 event turned out to be smaller than the warming during the 1997/1998 and 1982/1983 events. In contrast, during the 1997/1998 El Niño, a positive anomaly from the low-frequency variability mode amplifies the tropical eastern Pacific El Niño signal. A similar pattern also emerges during the 1982/1983 El Niño. In addition, the global warming mode contributes positively to these record-breaking El Niño events.

The asymmetry observed between El Niño and La Niña, with El Niño warming larger than La Niña cooling, can be understood via the same types of mechanisms that were described above. Negative and positive SST anomalies associated with the biennial oscillation mode are generally comparable in magnitude. Nonetheless, no strong La Niña events were observed during recent decades, since the negative anomalies from the biennial oscillation mode tend to be offset by positive anomalies from the low-frequency variability mode and the global warming mode. Since 1960, there was no instance where all three modes had negative anomalies.

A prolonged warming condition was observed over the tropical Pacific during the first half of the 1990s (orange shading in Fig. 8d). Many authors have described this unusual physical condition in detail (Ji et al. 1996; Kleeman et al. 1996; Goddard and Graham 1997; Gu and Philander 1997; Latif et al. 1997; Zhang et al. 1997). 
Fig. 8 Longitude-time cross section of the reconstructed SSTA based on the a first, b second, and c third CSEOF modes. d The Nino3 (black line) and Nino4 (blue line) indices of the raw SSTA data. The horizontal lines from top to bottom denote 1998/1999, $1976 / 1977$, and $1959 / 1960$ boundaries, respectively (a) Mode1

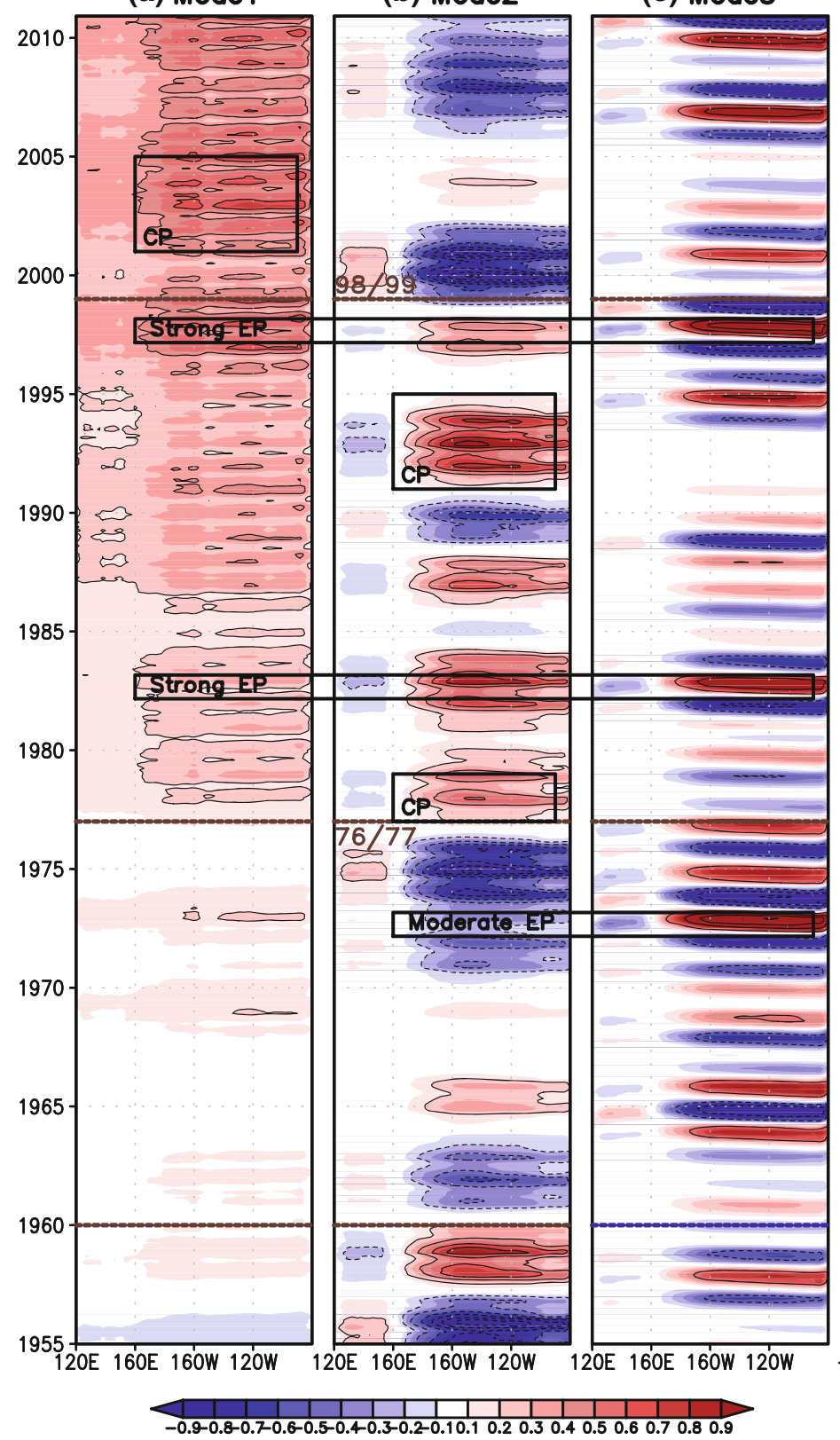

(d) Nino3\&4 index

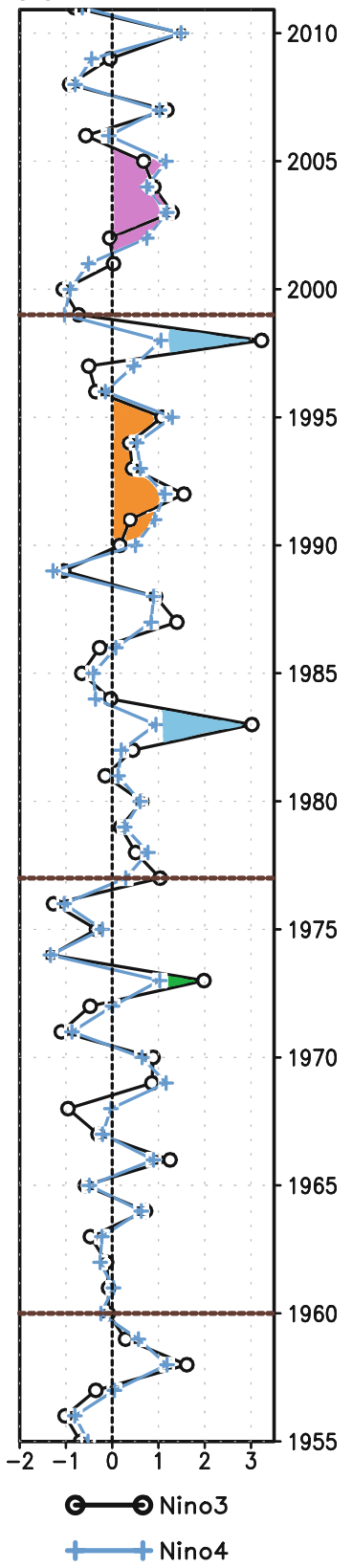

Recent studies have focused their attention on the warming that occurred in the CP region during the early 1990s El Niño (e.g., Kug et al. 2009; Yeh et al. 2009). During this period, the low-frequency variability mode shows striking positive anomalies (boxed area in Fig. 8b), while the amplitude of the biennial oscillation mode is negligible. Thus, it can be inferred that the warm anomaly in the tropical Pacific during the early 1990s is not associated with equatorial wave dynamics (Kim and Kim 2002). That is, the tropical warming during this period was not like a conventional ENSO. Rather, the anomalous warming condition originated mainly from the low-frequency variability mode. This interpretation is consistent with Latif et al. (1997), who concluded that the anomalous 1990s were dominated by the decadal mode, which was extracted via POP analysis. In addition, our study suggests that the global warming signal contributed to the anomalous 1990s, although the contribution from the global warming mode was smaller than that from the low-frequency variability mode. This conclusion is different from that of Latif et al. (1997), who concluded that global warming was not responsible for the anomalous 1990s.

As noted above, the sequence of El Niño events during the early 1990s were classified as CP El Niño events in previous 
studies (Kug et al. 2009; Yeh et al. 2009). These studies defined an event as a CPEl Niño if the Nino4 index exceeded the Nino3 index. Note that the Nino4 index is mostly larger than the Nino3 index during the time period ranging from 1990/1991 to 1994/1995, except for in 1991/1992 (Fig. 6d). However, even the 1991/1992 event has been classified as a CP El Niño according to several studies that used different CP El Niño definitions (Ashok et al. 2007; Kim et al. 2009; Yu and Kim 2010). The CP El Niño signature can be found in the low-frequency variability mode, with a maximum warming in the tropical central Pacific rather than the tropical eastern Pacific (see the boxed area in Figs. 8b and 2a). In particular, the CP El Niño of 1991/1992, 1992/1993, and $1993 / 1994$ conforms to the years of strong low-frequency variability. Similarly, the CP El Niño event during $1977 / 1978$ originated from the low-frequency variability mode (see the boxed area in Fig. 8b).

The CP El Niño is regarded to have occurred more frequently than the eastern Pacific (EP) El Niño during the 2000s (Yeh et al. 2009; Lee and McPhaden 2010; Yeo et al. 2012). The events in 2001/2002, 2002/2003, 2004/2005, and 2009/2010 were classified as CP El Niño events in previous studies (Kug et al. 2009; Yeh et al. 2009; Kim et al. 2009; Yu and Kim 2010). As shown by the Nino3 and Nino4 indices, there was a persistent warming in the tropical Pacific during the earlier 2000s (pink shading in Fig. 8d), which looked similar to the warming observed during the earlier 1990s (orange shading in Fig. 8d). Even after the linear trend is removed from the Nino3 and Nino4 indices, the prolonged warming during the earlier 2000s is still apparent (data not shown). To clarify the primary cause of tropical Pacific warming during the earlier 2000s, we examine how the three modes affect the tropical Pacific SSTAs during this time frame. In 1998/1999, the low-frequency variability mode transitioned to a cold phase, but the negative SSTA associated with this mode was insignificant during 2002-2006 (Fig. 8b). The amplitude of the biennial oscillation mode was also relatively small during this period. While the biennial oscillation and the lowfrequency variability modes were relatively weak, CP El Niño events were observed during this period (pink shading in Fig. 8d). Significant warming was seen only in the global warming mode during this period. Hence, the CP El Niño events that occurred during the early 2000s (i.e., 2001/2002, 2002/2003, and 2004/2005) were primarily driven by the global warming mode, and there were little contributions made by the low-frequency variability and biennial oscillation modes.

The latest CP El Niño event occurred in 2009/2010. As shown in Fig. 8, the 2009/2010 CP El Niño was primarily associated with positive anomalies in the global warming and biennial oscillation modes, and there was a relatively weak negative anomaly in the low-frequency variability mode. The sizable contribution from the biennial oscillation mode made the 2009/2010 CP El Niño event unique when compared to earlier CP El Niño events. Indeed, Kim et al. (2011) pointed out the unique structure of the 2009/2010 CP El Niño. For example, the 2009/2010 CP El Niño showed a record-breaking warm SSTA in the central Pacific (see Nino4 index in Fig. 8d), which then rapidly decayed to a La Niña state. These characteristics of the 2009/2010 CP El Niño appear to be associated with the biennial oscillation mode.

One major point emerges in this section and that is that the CP El Niño events in the early 1990s and the early 2000s appear to be driven by different physical mechanisms. That is, the CP El Niño events in the early 1990s originated mainly from the low-frequency variability mode, while those in the early 2000s were derived mainly from the global warming mode. In order to confirm this difference, composite maps of SSTAs are constructed based on the selected CP El Niño years of the 1990s and those of the 2000s (Fig. 9). The years 1991/1992, 1992/1993, and 1993/1994 are selected as CP El Niño years for the 1990s. Similarly, the years 2001/2002, 2002/2003, and 2004/2005 are selected as CP El Niño years for the 2000s. For the composite analysis, SSTAs are calculated based on 1955-2010 climatology and the winter-mean (averages from December to February) anomalies are used. As expected, the CP El Niño composite in the 1990s (Fig. 9a) reflects well with the characteristic features of the low-frequency variability mode, with the tropical central Pacific warming extending to the northeastern Pacific and the cold SSTAs in the central North Pacific. Meanwhile, the CP El Niño composite in the 2000s (Fig. 9b) clearly depicts a warming pattern consistent with the global warming mode. A similar statement can be made when SST anomaly is defined with respect to the 1871-2010 climatology (figure not shown).

The Nino3 and Nino4 indices are not found to represent an accurate depiction of physical and dynamical conditions in the tropical Pacific. Hence, the Nino3 and Nino4 indices are likely not appropriate criteria to use for describing physical and dynamical differences between EP El Niño and CP El Niño events. Figure 10 shows how the Nino3 and Nino4 indices (blue bars), which merely reflect total SSTA variability over the tropical Pacific, are comprised of distinct contributions from the global warming mode (green bars), the low-frequency variability mode (red curve), and the biennial oscillation mode (blue line). The sum of the three modes (gray dashed line) fit the Nino3 and Nino4 indices well. Each tropical Pacific warming/cooling event consists of a different combination of the three modes. Due to the distinct physical nature of the three modes, it should be imperative to distinguish the disparate sources of warming in the tropical Pacific. 
(a) 1990s CP (91/92, 92/93, 93/94)

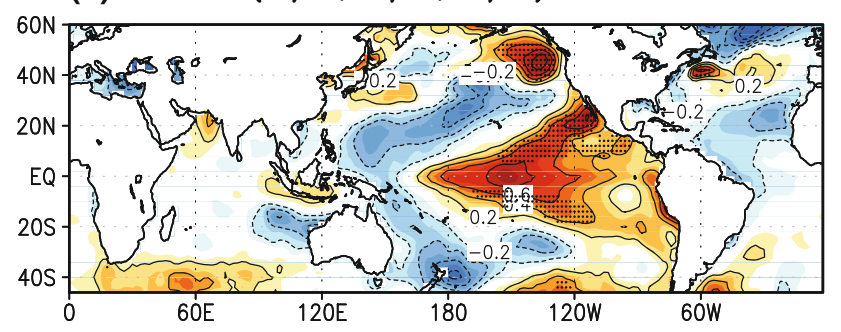

(b) 2000s CP $(01 / 02,02 / 03,04 / 05)$

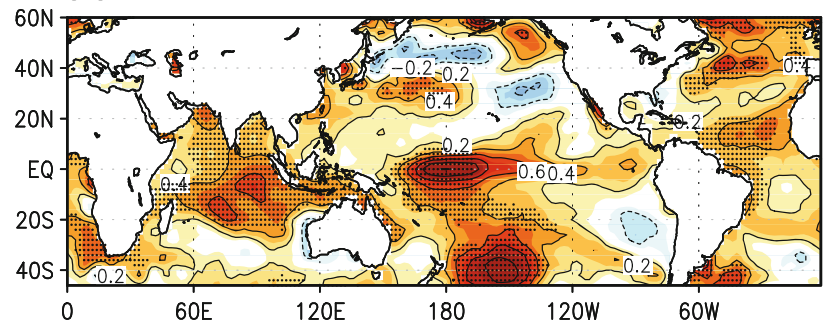

Fig. 9 a Composite map of the winter (December, January, and February) mean SSTA for the CP (central Pacific) El Niño years in the 1990s (1991/1992, 1992/1993, and 1993/1994), and b for the CP El Niño years in the 2000s (2001/2002, 2002/2003, and 2004/2005). Dotted areas reflect a $90 \%$ confidence for composite anomalies

\section{Summary and conclusions}

A CSEOF analysis was conducted to extract the principal modes of SST variability over the near-global domain during 1871-2010 based on the ERSST.v3 dataset. Three modes of SST variability were extracted. The first CSEOF mode represents the global warming signal. The loading patterns of the first mode exhibits positive SSTAs over much of the domain and more intense warming is seen in the tropical eastern and central Pacific than in the western Pacific, yielding an appearance of El Niño. In the second CSEOF mode, positive SSTAs in the tropical Pacific are connected with SSTAs of the same sign in the western shore of North America along with negative SSTAs over the western to central North Pacific. The temporal evolution pattern of the second mode indicates that this mode represents low-frequency variability with a strong connection between the North Pacific and the tropical Pacific. The third mode displays biennial oscillation and depicts transitions between El Niño and La Niña over 2-year periods. The third mode fits the canonical picture of ENSO, in which the oscillation mechanism created by tropical Pacific waves dominated. These three principal modes of SST variability are found to be nearly independent of each other. Together, the three modes reproduce the majority of observed SSTAs in the tropical Pacific. In other words, the bulk of ENSO variability is adequately explained in terms of the interplay among the three modes. The irregular interplay of the three modes has profound implications for physical and dynamical interpretations of ENSO events.

It is identified that the low-frequency and biennial components of the tropical Pacific SST variability constitute the intrinsic feature of ENSO. Recently, however, ENSO characteristics are significantly affected by global warming. How global warming affects ENSO variability can be understood by comparing the ENSO characteristics before 1960 with those in the recent decade. In 1914/1915, both the low-frequency variability and the biennial oscillation modes exhibit positive SSTA (see Figs. 2c, 3c), which is similar to the strong El Niño events in 1982/1983 and 1997/1998 (see Fig. 8). The intensity of the 1914/1915 El Niño as measured by the Nino3 index, however, is approximately one-third of that of the 1982/1983 El Niño, which is mainly due to the negative sign of the global warming mode.

Several years of negative SSTA in the low-frequency variability mode and positive SSTA in the biennial oscillation mode are identified in the dataset (e.g., 1937/1938, 1943/1944, 1972/1973, 1974/1975, 2006/2007, and 2009/2010). As shown in Fig. 1c, the global warming signal is obscure in 1937/1938, 1943/1944, 1972/1973 and 1974/1975 events. Thus, these years are classified as nonENSO years, since the low-frequency and the biennial oscillation modes tend offset each other (see Nino3 or Nino4 indices in Fig. 5); an exception is the 1972/1973 El Niño when the positive SSTA in the biennial oscillation mode was extremely strong. On the other hand, warming in the tropical Pacific is significant during the years of 2006/2007 and 2009/2010, despite the opposite sign of SSTAs in the lowfrequency variability and biennial oscillation modes (Fig. 8). It appears that El Niño events in these years were strongly affected by the conspicuous global warming signal.

There has been no significant change in the strength of the low-frequency variability and the biennial oscillation modes (red curve and blue line in Fig. 10) with the advancement of global warming. As can be seen in the PC time series of the two modes (Figs. 2b, 3b), there was no indication that these intrinsic features of ENSO have varied in any substantial way over the last 100 years (1910-2010), during which sea surface temperatures in the equatorial Pacific $\left(120^{\circ} \mathrm{E}-80^{\circ} \mathrm{W}\right.$, $20^{\circ} \mathrm{S}-20^{\circ} \mathrm{N}$ ) rose by about $0.65^{\circ} \mathrm{C}$. There was also no sign of more frequent CP El Niño events or less frequent La Niña events during the last century in the low-frequency variability and the biennial oscillation modes. Hence, it is likely that continued warming in the tropical Pacific was responsible for the apparent increase in the occurrence frequency of $\mathrm{CP}$ El Niño events and the decrease in the frequency of $\mathrm{La}$ Niña events during recent decades.

An important question to consider is whether or not the results presented here are dependent on the dataset or the analysis period. The results presented in this study are not overly sensitive to the employed dataset. Analyses based on 
Fig. 10 Nino3 (upper panel) and Nino4 (lower panel) time series (blue bars) decomposed into contributions from the global warming (green bars), low-frequency variability (red curves), and biennial oscillation (blue line) modes. The dashed gray line represents the sum of the three modes. The boxes in the upper panel denote years of strong EP (eastern Pacific) El Niño events and those in the bottom panel denote years of strong CP El Niño events
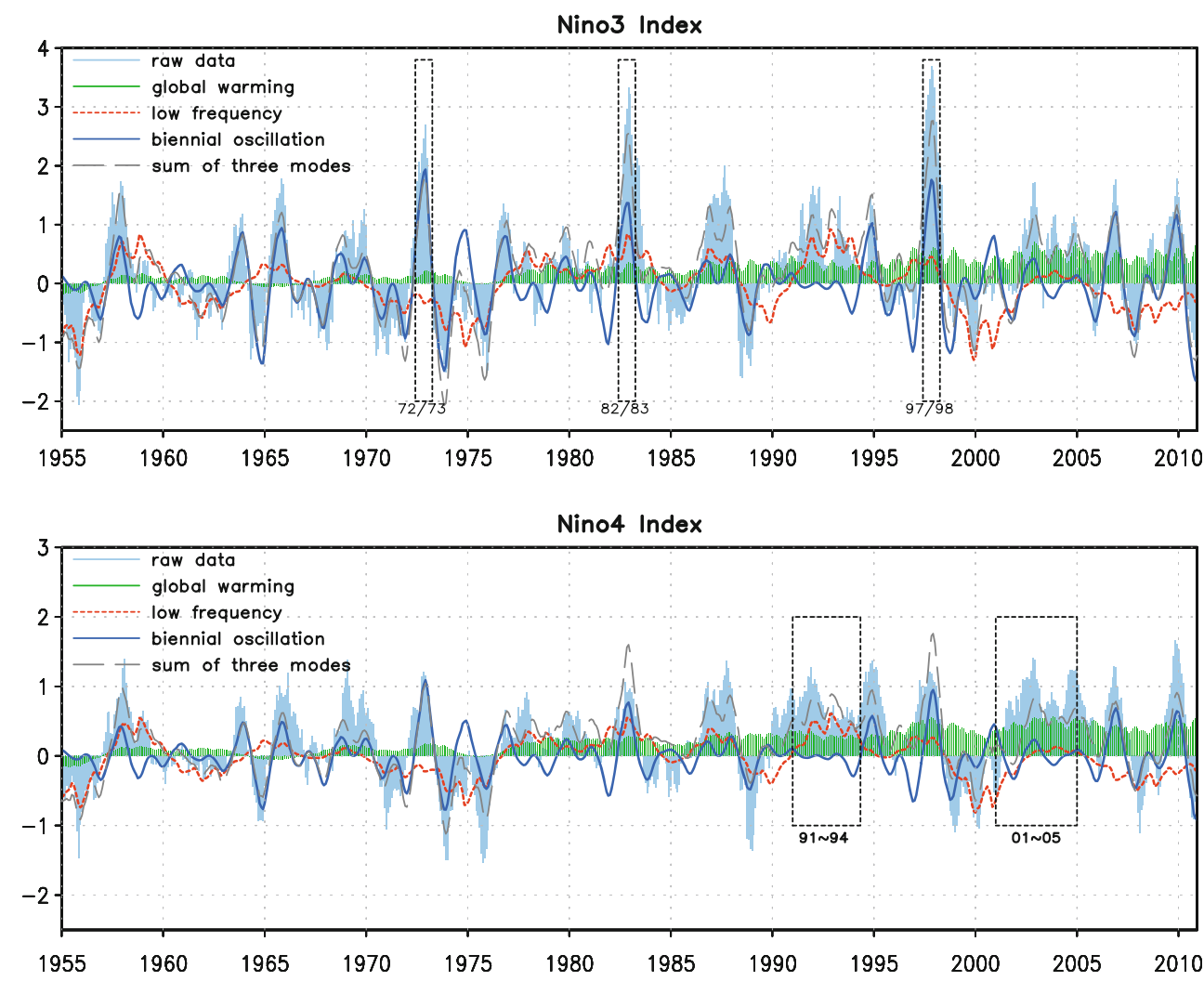

Hadley Centre Sea Ice and Sea Surface Temperature (HadISST) (Rayner et al. 2003) and Kaplan SST (Kaplan et al. 1998) datasets yield virtually identical results to those presented in Sects. 3 and 4. Even though the three SST datasets (i.e., ERSST.v3, HadISST, and Kaplan SST) have different spatial resolutions, the first three CSEOF modes are quite similar among the three datasets. This level of consistency adds robustness to the results obtained in the present study. Numerous data spanning the twentieth century are typically required to discriminate the global warming signal from decadal fluctuations. Although the ERSST.v3 dataset used in this study was based on sparse observations in early years, an improved statistical method helped to make the dataset suitable for use in studying basin-wide features typical of ENSO and interdecadal variability.

The loading vectors (spatial patterns) of the three modes were mostly orthogonal to each other over the nested period. However, over the tropical Pacific the loading vectors of the low-frequency variability and the global warming modes were not mutually orthogonal but were strongly correlated. Thus, the distinction of the three modes in the tropical Pacific requires an inspection of SSTAs outside of the tropical Pacific.

Our analysis based on the principal modes of SSTA provides only a partial indication of the diverse processes that can affect the patterns and physical characteristics of ENSO. Since ENSO is a highly coupled ocean-atmosphere phenomenon, it will be necessary to extract atmospheric evolution patterns that are physically consistent with the three SSTA modes (see Figs. 6, 7) for future studies. Nevertheless, the decomposition of tropical Pacific SST variability into the three independent modes and the associated derivation of physical and statistical inferences signify a need for more accurate and sensible approaches for studying ENSO from physical and dynamical viewpoints.

Acknowledgments This research was supported by the project entitled "Ocean Climate Change: Analysis, Projections, Adaptation (OCCAPA)" funded by the Ministry of Land, Transport, and Maritime Affairs, Korea. SRY acknowledges the support by the Global Ph.D. Fellowship program.

Open Access This article is distributed under the terms of the Creative Commons Attribution License which permits any use, distribution, and reproduction in any medium, provided the original author(s) and the source are credited.

\section{References}

Alexander MA, Blade I, Newman M, Lanzante JR, Lau NC, Scott JD (2002) The atmospheric bridge: the influence of ENSO teleconnections on air-sea interaction over the global oceans. J Climate 15(16):2205-2231

Ashok K, Behera SK, Rao SA, Weng H, Yamagata T (2007) El Niño Modoki and its possible teleconnection. J Geophys Res 112:C11007

Barnett TP (1991) The interaction of multiple time scales in the tropical climate system. J Climate 4(3):269-285 
Barnett TP, Pierce DW, Latif M, Dommenget D, Saravanan R (1999) Interdecadal interactions between the tropics and midlatitudes in the Pacific Basin. Geophys Res Lett 26(5):615-618

Battisti DS, Hirst AC (1989) Interannual variability in a tropical atmosphere-ocean model: influence of the basic state, ocean geometry, and nonlinearity. J Atmos Sci 46:1687-1712

Bjerknes J (1969) Atmospheric teleconnections from the equatorial pacific. Mon Weather Rev 97(3):163-172

Boer G, Yu B, Kim S-J, Flato G (2004) Is there observational support for an El Niño-like pattern of future global warming? Geophys Res Lett 31(6):L06201

Bond N, Overland J, Spillane M, Stabeno P (2003) Recent shifts in the state of the North Pacific. Geophys Res Lett 30(23):2183

Cai W, Whetton PH (2000) Evidence for a time-varying pattern of greenhouse warming in the Pacific Ocean. Geophys Res Lett 27(16):2577-2580

Collins M (2005) El Niño-or La Niña-like climate change? Clim Dyn 24(1):89-104

Compo GP et al (2011) The twentieth century reanalysis project. Q J Geol Meteorol Soc 137:1-28

Deser C, Phillips AS, Alexander MA (2010) Twentieth century tropical sea surface temperature trends revisited. Geophys Res Lett 37 (L10701). doi:10.1029/2010GL043321

Goddard L, Graham NE (1997) El Niño in the 1990s. J Geophys Res 102(C5):10423-10436

Gu D, Philander SG (1997) Interdecadal climate fluctuations that depend on exchanges between the tropics and extratropics. Science 275(5301):805-807

Ji M, Leetmaa A, Kousky VE (1996) Coupled model predictions of ENSO during the 1980s and the 1990s at the National Centers for Environmental Prediction. J Climate 9(12):3105-3120

Jin FF (1997a) An equatorial ocean recharge paradigm for ENSO. Part I: conceptual model. J Atmos Sci 54(7):811-829

Jin FF (1997b) An equatorial ocean recharge paradigm for ENSO. Part II: a stripped-down coupled model. J Atmos Sci 54(7):830-847

Kao HY, Yu JY (2009) Contrasting eastern-Pacific and central-Pacific types of ENSO. J Climate 22:615-632

Kaplan A, Cane MA, Kushnir Y, Clement AC, Blumenthal MB, Rajagopalan B (1998) Analyses of global sea surface temperature 1854-1991. J Geophys Res 103(18):567-589

Kim KY (2002) Investigation of ENSO variability using cyclostationary EOFs of observational data. Meteorol Atmos Phys 81(3):149-168

Kim KY, Kim YY (2002) Mechanism of Kelvin and Rossby waves during ENSO events. Meteorol Atmos Phys 81(3):169-189

Kim KY, North GR (1997) EOFs of harmonizable cyclostationary processes. J Atmos Sci 54(19):2416-2427

Kim KY, North GR, Huang J (1996) EOFs of one-dimensional cyclostationary time series: computations, examples, and stochastic modeling. J Atmos Sci 53(7):1007-1017

Kim H, Webster P, Curry J (2009) Impact of shifting patterns of Pacific Ocean warming on north Atlantic tropical cyclones. Science 325:77-80

Kim W, Yeh SW, Kim JH, Kug JS, Kwon M (2011) The unique 2009-2010 El Niño event: a fast phase transition of warm pool El Niño to La Niña. Geophys Res Lett 38(15):L15809

Kleeman R, Colman R, Smith N, Power S (1996) A recent change in the mean state of the Pacific basin climate: observational evidence and atmospheric and oceanic responses. J Geophys Res 101(C9):20483-20499

Kleeman R, McCreary J, Klinger B (1999) A mechanism for generating ENSO decadal variability. Geophys Res Lett 26(12):1743-1746

Kug JS, Kang IS (2006) Interactive feedback between ENSO and the Indian Ocean. J Climate 19(9):1784-1801

Kug JS, Jin FF, An SI (2009) Two types of El Niño events: cold tongue El Niño and warm pool El Niño. J Climate 22:1499-1515
Larkin NK, Harrison D (2005) Global seasonal temperature and precipitation anomalies during El Niño autumn and winter. Geophys Res Lett 32:L16705

Latif M, Kleeman R, Eckert C (1997) Greenhouse warming, decadal variability, or El Niño? An attempt to understand the anomalous. J Climate 10(9):2221-2239

Lau NC, Nath MJ (1996) The role of the "atmospheric bridge" in linking tropical Pacific ENSO events to extratropical SST anomalies. J Climate 9(9):2036-2057

Lee T, McPhaden MJ (2010) Increasing intensity of El Niño in the central-equatorial Pacific. Geophys Res Lett 37(14):L14603

Mantua NJ, Hare SR, Zhang Y, Wallace JM, Francis RC (1997) A Pacific interdecadal climate oscillation with impacts on salmon production. Bull Am Met Soc 78(6):1069-1080

Meehl GA, Washington WM (1996) El Niño-like climate change in a model with increased atmospheric $\mathrm{CO}_{2}$ concentrations. Nature 382(6586):56-60

Miller AJ, Cayan DR, Barnett TP, Graham NE, Oberhuber JM (1994) The 1976-77 climate shift of the Pacific Ocean. Oceanography $7(1): 21-26$

Minobe S (2000) Spatio-temporal structure of the pentadecadal variability over the North Pacific. Prog Oceanogr 47(2):381-408

Neelin JD, Battisti DS, Hirst AC, Jin F-F, Wakata Y, Yamagata T, Zebiak SE (1998) ENSO theory. J Geophys Res 103(C7):14261-14290

Peterson WT, Schwing FB (2003) A new climate regime in northeast Pacific ecosystems. Geophys Res Lett 30(17):1896

Pierce DW, Barnett TP, Latif M (2000) Connections between the Pacific Ocean tropics and midlatitudes on decadal timescales. J Climate 13(6):1173-1194

Rasmusson EM, Carpenter TH (1982) Variations in tropical sea surface temperature and surface wind fields associated with the Southern Oscillation/El Niño. Mon Weather Rev 110(5):354-384

Rasmusson EM, Wang X, Ropelewski CF (1990) The biennial component of ENSO variability. J Mar Syst 1(1):71-96

Rayner N, Parker D, Horton E, Folland C, Alexander L, Rowell D, Kent E, Kaplan A (2003) Global analyses of sea surface temperature, sea ice, and night marine air temperature since the late nineteenth century. J Geophys Res 108(D14):4407

Schwing F, Moore C (2000) A year without summer for California, or a harbinger of a climate shift? EOS Trans 81:301-305

Smith TM, Reynolds RW, Peterson TC, Lawrimore J (2008) Improvements to NOAA's historical merged land-ocean surface temperature analysis (1880-2006). J Climate 21(10):2283-2296

Suarez MJ, Schopf PS (1988) A delayed action oscillator for ENSO. J Atmos Sci 45(21):3283-3287

Timmermann A, Oberhunber J, Bacher A, Esch M, Latif M, Roeckner E (1999) Increased El Niño frequency in a climate model forced by future greenhouse warming. Nature 398:694-697

Trenberth KE, Hoar TJ (1996) The 1990-1995 El Niño-Southern Oscillation event: longest on record. Geophys Res Lett 23(1): $57-60$

Vimont DJ, Wallace JM, Battisti DS (2003) The seasonal footprinting mechanism in the Pacific: implications for ENSO. J Climate 16:2668-2675

Yeh SW, Kug JS, Dewitte B, Kwon MH, Kirtman BP, Jin FF (2009) El Niño in a changing climate. Nature 461(7263):511-514

Yeo SR, Kim KY, Yeh SW, Kim W (2012) Decadal changes in the relationship between the tropical Pacific and the North Pacific. J Geophys Res 117(D15):D15102

Yoo SH, Fasullo J, Yang S, Ho CH (2010) On the relationship between Indian Ocean sea surface temperature and the transition from El Niño to La Niña. J Geophys Res 115:D15114

Yu JY, Kim ST (2010) Three evolution patterns of Central-Pacific El Niño. Geophys Res Lett 37(L08706). doi:10.1029/2010GL042810

Zhang Y, Wallace JM, Battisti DS (1997) ENSO-like interdecadal variability: 1900-93. J Climate 10(5):1004-1020 